\title{
Computer -aided Machine Tool Selection (Numerical or conventional) with respect to Cost Assessment (CAMTS)
}

\author{
By
}

\author{
I. M. Elewa
}

Assoc. Prof. Dr. in Indust. Prod Eng. Dept.

Faculty of Eng. Mansoura Univ.

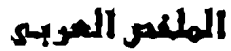

\section{استخدام الحاسب الالمى فى الختيار ماكينة التتشغيل

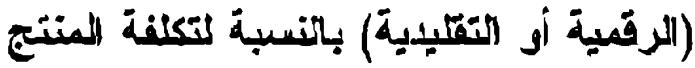

لاتستفم المكينات الرقية فى الاتتاج الفزير ولكن تستخدم بنجاح فى تشغيل المنتجات ذات الاعداد الصنيرة

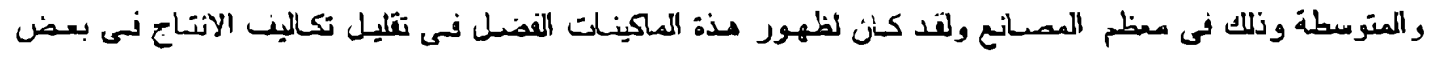

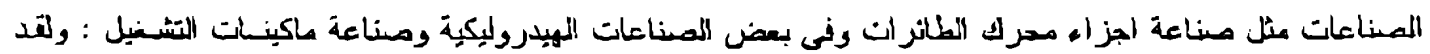

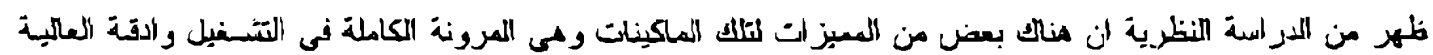

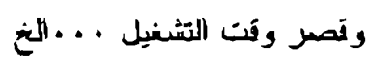

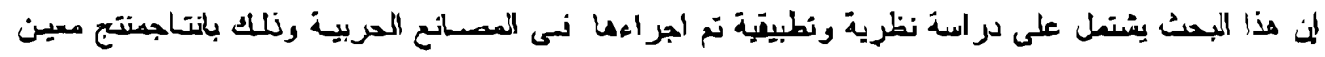

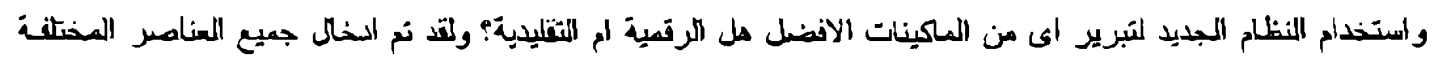

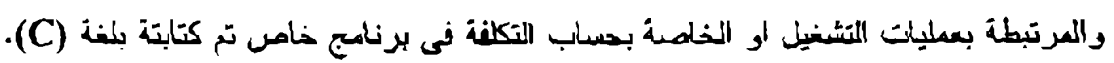

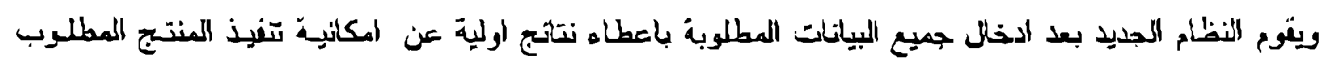

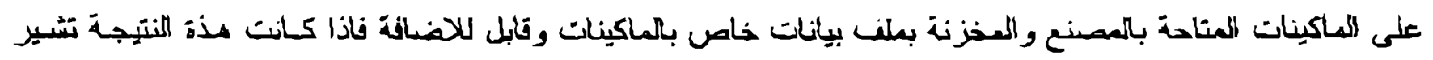

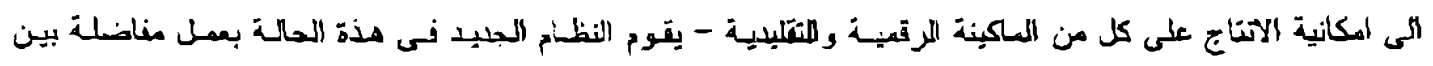
الماكينتين على اساس المكلفة الكلية.

\footnotetext{
Abstract

Numerical control $\mathrm{m} / \mathrm{c}$ tools are not intended to compete with mass production process $\mathrm{NC}$ techniques are applied most successfully when components are machined in small batches, The machining of small and median quantities is a high cost area of production.

The advent of NC provides a medium for reducing machining costs in low quantity production which is of particular value in cerain types of industry engineering aircraft accessory, hydraulic and machine tools. The study has shown several factors in favor of NC such as full flexibility, accuracy, shorter production time, etc. The present work has an expermencal study which carried out in one of the military factoncs to establish a justification rule for producing a certain product.
} 
The riationship between the variables such as the tolerance required for dimension. shapes, and surface roughness as well as the process capability has been encountered in a special program written in Clanguage

The availability of producing each feature in the product has been checked for each $\mathrm{m} / \mathrm{c}$. If the decision is the two $\mathrm{m} / \mathrm{C}$ can be produce the product or feature then the cost analysis will takes place.

\section{Introduction}

Numerically controlled machine tools have become standard features in the manufacturing facilities of today. Since these tools began making their way into industry around 1957, their capabilives have increased greatly. The evolucion of the field of numerical control has introduced industry to such concepts as CAD/CAM, flexible manufacturing system and many others ( 1 )

It has bentimated that most manufactured parts are produced in lot sizes of 50 or fcwer, small lot and batch production jobs, present the ideal situations for the application of NC This is made possible by the capability to program the NC machine and to save that program for subsequent use in furure orders. If the NC programs are long and complicated, complex part geomery, many operations, much metal removal, This makes NC all the more appropriate when compared to manual methods of production. finally, if quality and unspection are important issues (close tolerances, high part cost, 100\% inspection required), NC would be most suicabie, owing to its high accuracy and repeatability. $(2,3)$ Repeatability is the comparison berween the same dimensions of each piece machined.

The repeatability of NC is roughly about one-half of the actual positioning tolerances. Repeatability is another important goal of modern NC manufactures and users. The skilled bands of a good machinist are difficult to find. Thus the reliability that was previously built into the hands of the machinist must now be built unto the NC machire. $(4,5)$. NC machines provide good position accuracy and repeatability, complex jigs and fixture are not required in all cases. Also, a high degree of quality is inherent in the NC process because of accuracy: repeatability and freedom from operator-introduced variations. In-process quality inspection is seldom required after an inspection of the first part produced. from a new tape, as a check on the programming function (6).

One of the basis functions of economic planaing is the determination of lor size. With conventional machuning methods, setup costs are high and carnot be calculated with any degree of accuracy, The refor it is necessary to make a large number of parts for each setup if the unit part cost is to be minimized. With numcrically controlled machined the high process predictability ensures accurate cost determinations, and the simplified, low cost setups enables parts to be nun in small quantities economically $(6,7)$

Horvever, there are a multiplicity of factors influencing calculations to establish beyond doubt the most suitable field of applications for NC tuming machines (8) in this context it must not be forgotten that improvements in economy are not achieved only by reducing direct production costs. There are quite number of other cost factors which influence economical production without appearing directly as production costs. NC machines have adhesive influence on the overall production flow, the design of production media and the whole chain of events from work preparation to the final inspection. Also, the quality costs are usually estimated to be at least $10-15 \%$ of the product costs. About $60-70 \%$ the quality costs are thought to depend on the enrors of the produced parts (geometrical accuracy) due to insufficient control of the machining process. Even laading of workpieces, automation of tool clange, wear of the tool or tool failures, influence product quality when manual supervision is reduced or eliminated $(9,10,11,12)$.

\section{The area of comparability}

In an economic comparison between two conventional machining processes, say between tuming on a center lathe and turning on a capstan lathe, it is a often sufficient to make a direct concrast between the floorto-floor time for the two processes and select the process neding the least time for production. This comparison is possible if the costs of machine operation and tooling are similar. If the turning and tooling costs are not similar e.g. as berween a drilling and a jig boring machines, then the comparison must zake into account the costs of each process and not simply the time for each opention. 
Making a decision on a basis of time can be done on the shop floor. deciding on a basis of cost requres the use of information which can be supplied by the cost account, and the decision is usually carred out in the planing department. The direct approach outlined above can be used for economit comparison of circumstances surrounding, each of the process are themselves directly comparable. The some administration is shared, the planning procedures are identical, there is no difference in the supporting services to the machine, e.g. tool stores, maintenance, etc. This is not tne when companng NC with conventional machining processes. a moment's through will show differences in the following areas:

a. The preparation work, e.g. programming and tape preparation is not needed for conventional machenes:

b. Backing-up services, e.g. pre-set tooling and computer services, may be needed for NC work. (10)

c. Workshop floor facilities, e.g. large amount of jig storage space are not required for NC production.

\section{Factors to be considered in the comparability between the conventional $\mathrm{m} / \mathrm{c}$ and $\mathrm{NC}$.}

It is possible to assess certain factors directly in monetary terms. For exanple, the actual product cost including the cost of labor and over heads antribute able to the process-can be determined. Sening-up costs can be contrasted with the set-up costs of conventional methods, and the value of machining centers can be checked

Mony factors which affect costs one way on the other remain unconsidered. To ensure that these factors are not overlooked they are summarized below. The savings made in these areas should always be taken into consideration, and the effect of NC production will not be fully appreciated until the impact in all areas has been evaluated and the different are : areas inspection costs, the cost of scrap, the machining accuracy, the cost of modification. the tool storage costs, the transportation costs, the machinc utilization, the cost of floor space and the work in-progress.

\section{Decision making for deciding between NC and conventional machining.}

Both NC and conventional machining have their relative advantages and disadvantages. However, it is not always obvious whether a particular part should be processed benefits of NC, only these parts that are appropriate for NC must be processed on it. Currently, there is no universally accepted procedure for deciding on parts to the experience of the process planner and the facilities available within the $m / c$ shop. When the choice between NC and eonventional machine tool is not clear, altemative process plans must be developed for both methods $A$ study was conducted in several of the machine shops to develop a standard scoring system and decision table for determining whether to process a part on a NC or on conventional equipment. (13). In the use of the scoring system, an analysis is made of the physical characteristics shown on the part print and of other known information about the part, such as lot size, lots/year, ... etc.

These factors are assigned weighting values The assigned factors are then summed up, and a decision is made weather to produce the part by NC or by conventional methods, depending on the sum of the factor weights.

The procedure consists of two steps, the first step is concemed with a conditional decision, if numencal control were to be used, what type of NC machine would it be ? The second step involve a comparison of the relative merits of using conventional processing methods against the particular NC machine selccted in the first step. This comparison involves the use of 22 process planning factors that might influence the decision on processing method. Each factor is assigned a value which depends on the part characteristics, the values are added and if the sum exceeds a cerrain threshold value, NC should be used; otherwise, conventional machines should be used.

\section{Cost comparison: NC and Conventional machine processes.}

To detennine weather NC or conventional methods are the most economic in a given circumstances, the calculation made must take into account the factors which have been discussed. To provide a basis for the calculation, it is essential for the relevant data regarding costs to be available and for estimates to be made of the expected times needed for carrying out the various activities, e.g. planning, programming, ...etc. The break-even point can then be determined and the relative economics of the two process assessed. 
The dala needed for the comparison falls into two distinct parts : (a) Data relating to the time taken for preparing for production setting-up and machining. the data (a) need be determined once only for subsequent cajcularions, but data (b) must be calculated for each individual component for which an economic comparison of the processes is made

\section{The program design.}

The program is designed to be used directly by the production cngineer personnel. The program requires IBM pc or IBM compatible, hard disk 170 MB and 2MB RAM, a high resolution card (EGA card at least), and color monitor.

The program was designed as friendly system to produce a good interface between the user and the program. The program is writen with a high level computer language is namely $\mathbf{C}$.

The user of this program works directly from the detail drawing. This program has the ability to select the suitable machine for each feature according to the specification required as well as the ability to justify the suitable $\mathrm{m} / \mathrm{c}$ according to the total cost of the product.

The main characteristics of the program are:

1. Detecting the type of the required $\mathrm{m} / \mathrm{c}$ for a specific component according to; IT grade (dimension, form errors, surface roughness) and the geometry of the component (Max. diameter, Max. length).

2. Searching in a store data base files 1,2 where: data base file 1 for conventional $m / c$ and data base file 2 for numerical control (NC).

- If the answer is yes the two type of $\mathrm{m} / \mathrm{C}$ capable to produce this component then the justification of use which are according to the total cost will takes place. But if the answer is No then return to the main menu.

3. Updating data base stored for both conventional $m / C$ and numerical $m / C$. The flow chart of this program is shown in Fig. 1. The data file is written with special format and contains required input of the program.

The input of the program is :

- Detecting number from the main menu (q).

- The form number (num) which contain the operation type.

- The required grade number (it)

- Max diameter (s1) and max. length of the workpiece (s2).

The flow chart of the lotal cost has shown in Fig. 2. The main function cost in this program are, The preparation cost, related cost and machining cost and the program is capable to extend for any other type of cost.

The flow chart of justification of use which $\mathrm{m} / \mathrm{c}$ has shown in Fig. 3 and the output chart showng the break even point (BEP) is illustrated in Fig. 4.

the output of the run program and nomenclature showing in appendix $I$.

\section{7-Practical application.}

In order to check the applicability of the created systern a certain component has been produce in the military factory as shown in Fig. 5 . first the check has been done based on the process capability of each $\mathrm{m} / \mathrm{c}$ (conv.\& $\mathrm{Nc}$ ). When the answer is yes, the two $\mathrm{m} / \mathrm{c}$ are capable to produce this component according to the required specification, then the justification of use which $\mathrm{m} / \mathrm{c}$ according to the total cost will takes place.

To carry out this justification it was necessary to find out the values of different elements of cost i.e. the preparation cost, the related cost and the machining cost.

The process planning office has done all the required steps, i.e. the process sequence, for both conventional and numierical from which the preparation and the machining cost has obtained as shown in Fig.6 for numerical $\mathrm{m} / \mathrm{c}$ and in fig Fig. 7 for conventional $\mathbf{m} / \mathrm{c}$. 


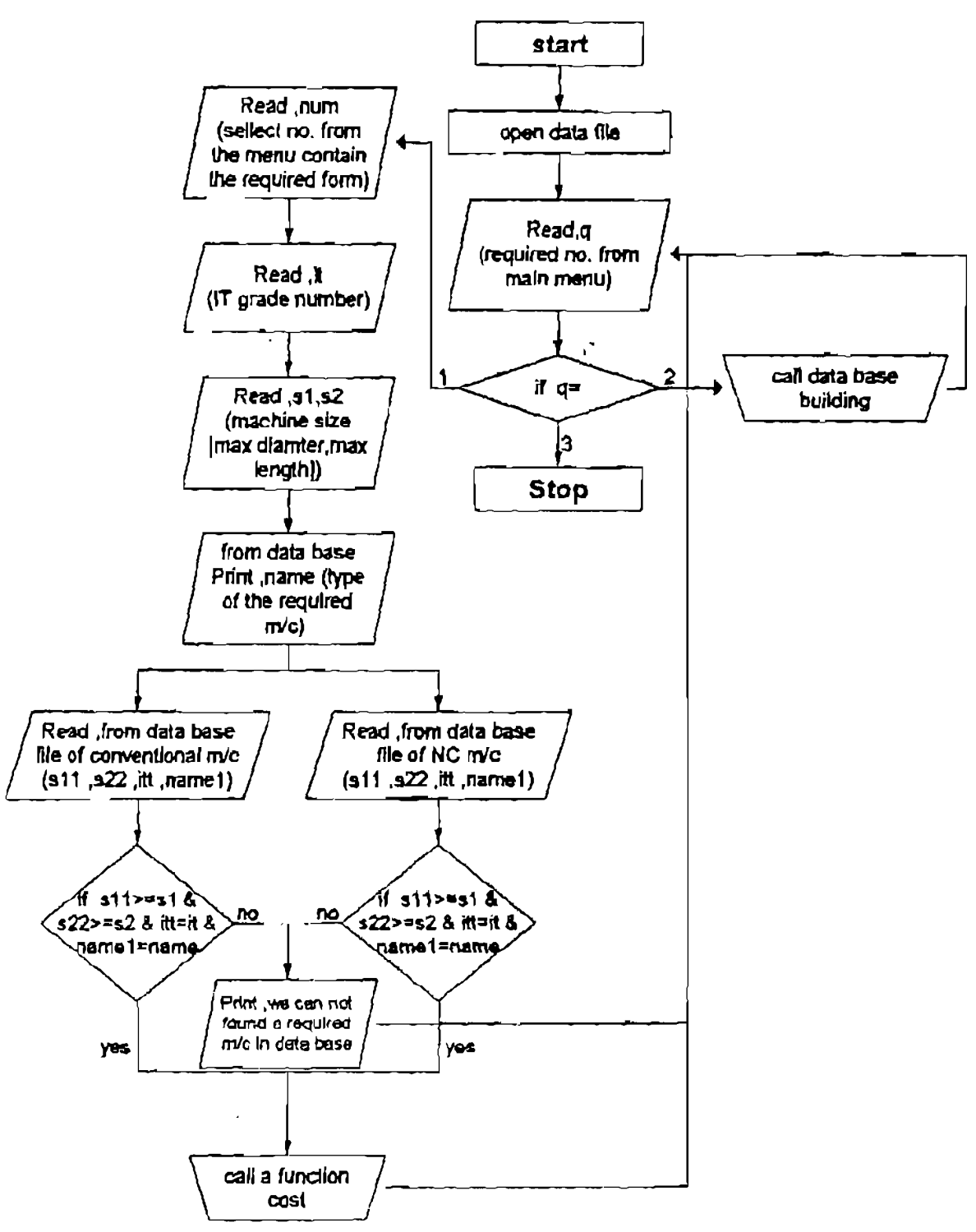

Fig. 1. The flow chart of the main program 
M 125, I. M. Elewa
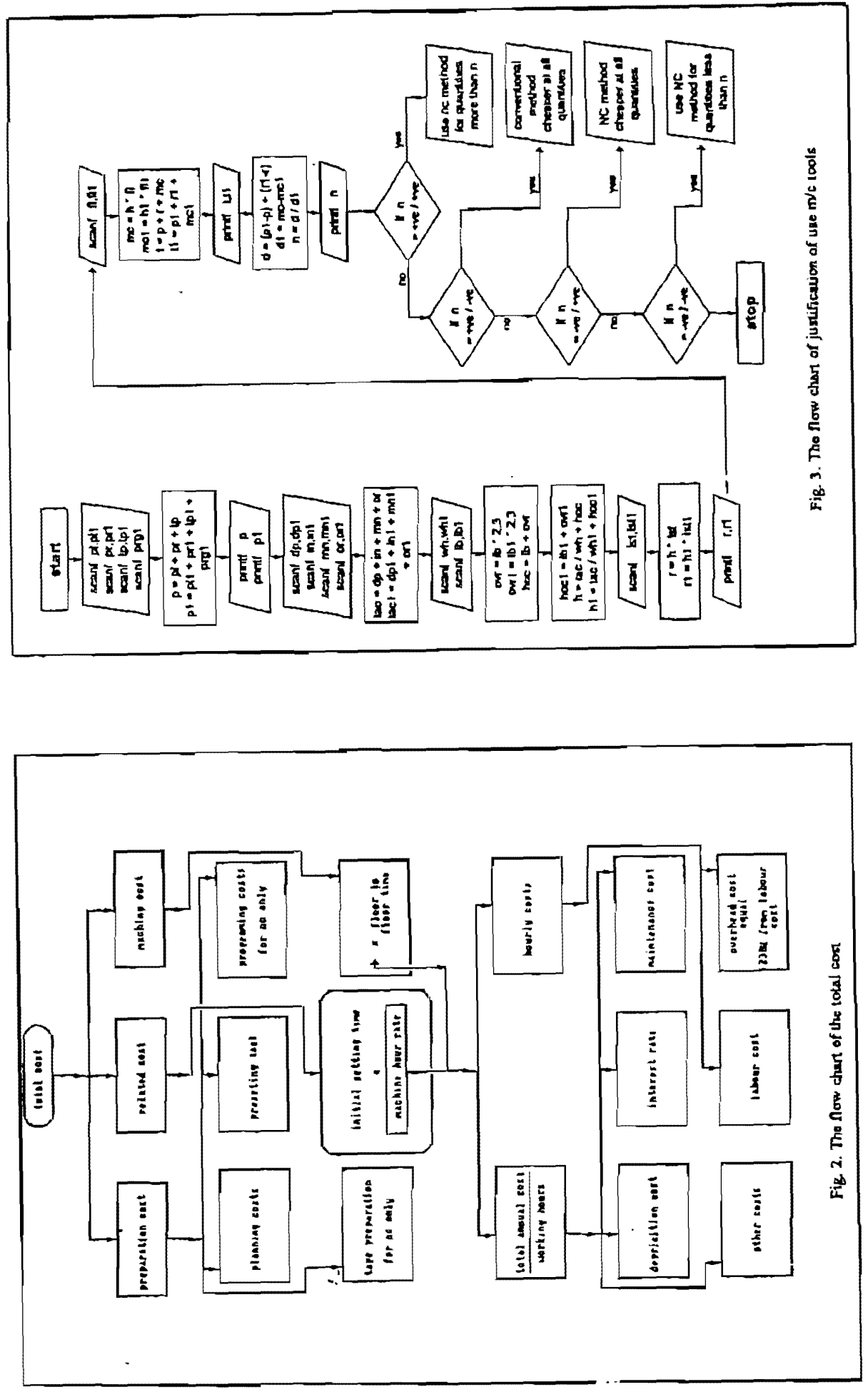


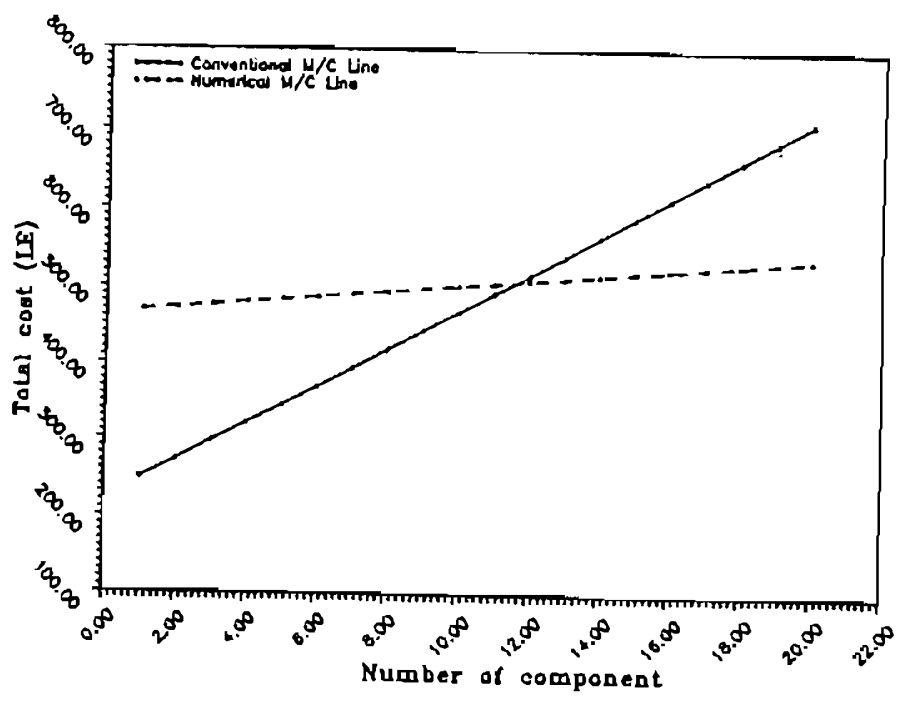

Fig 4. Ouput chart showing the breakeven poird (BEP)

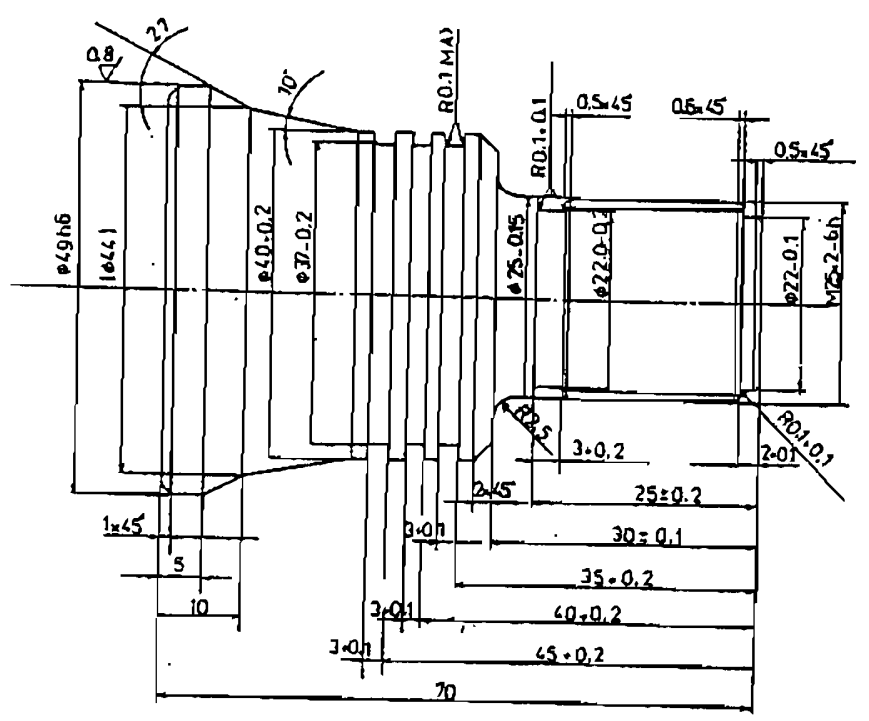

T10 tor Turing

t3o cor turing wich noze Rz.s

Tas Groving

T30 Cor Thrnading

Fig. 3. The warkpiece goomely which prodeced using corvantional and NC aves 


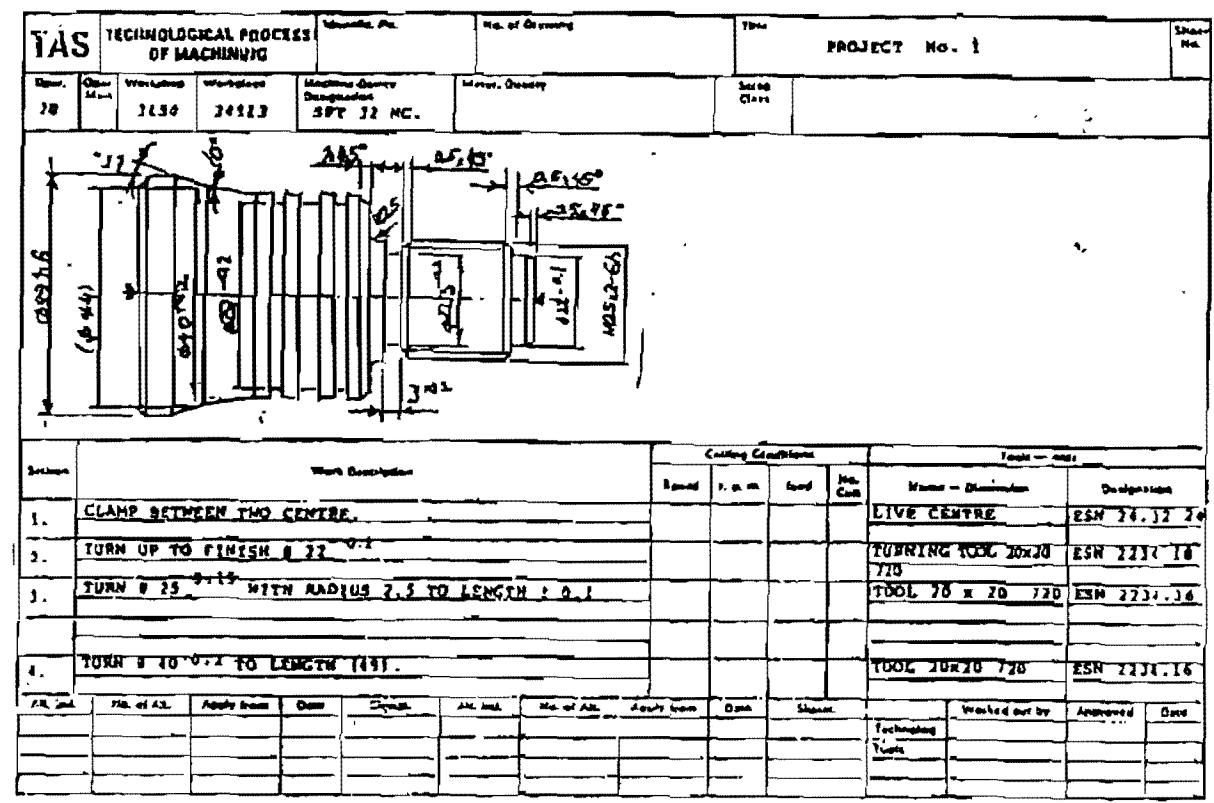

Fig 6a. The process sheel for operalion NO. 20 using NC m/c

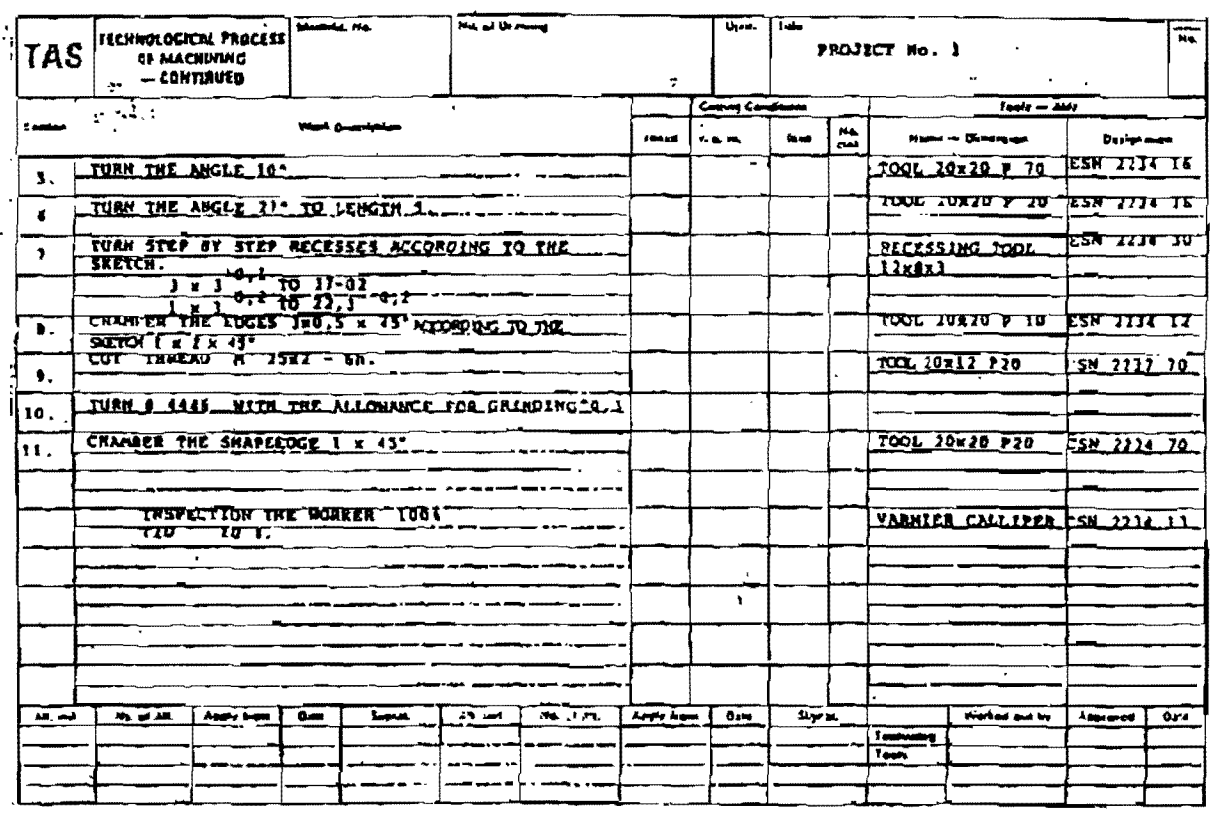

Fig.6b. 


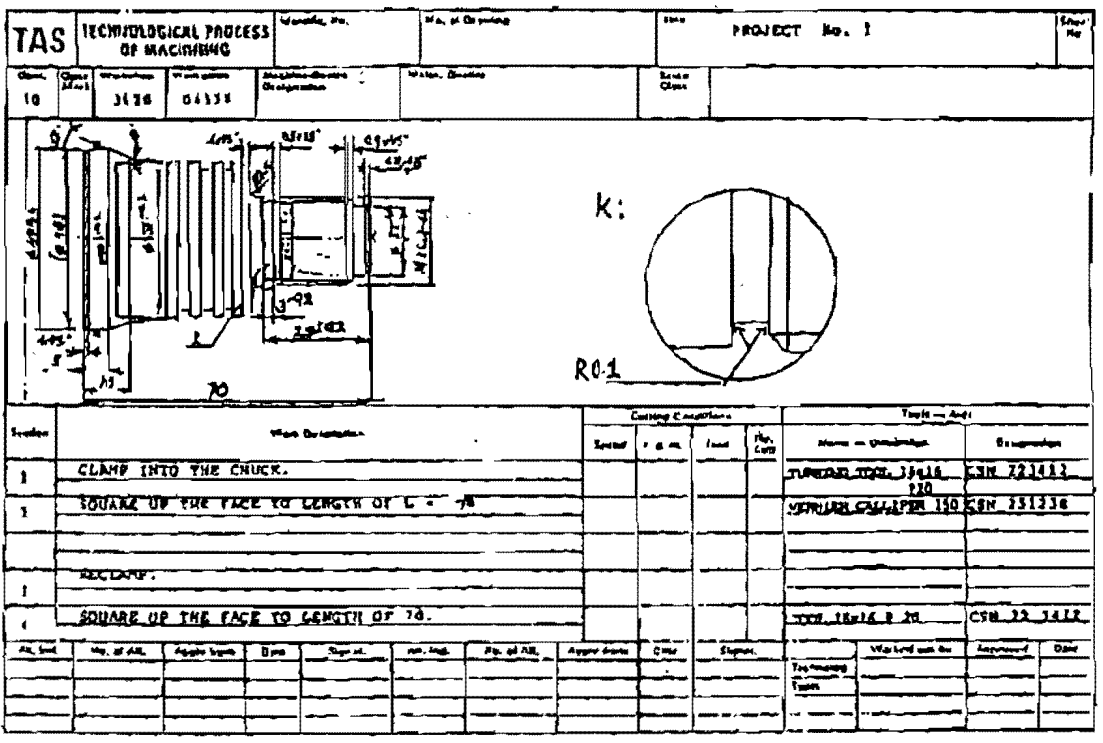

Fig. is the process sticet for operation NO. 10 using corventional mie

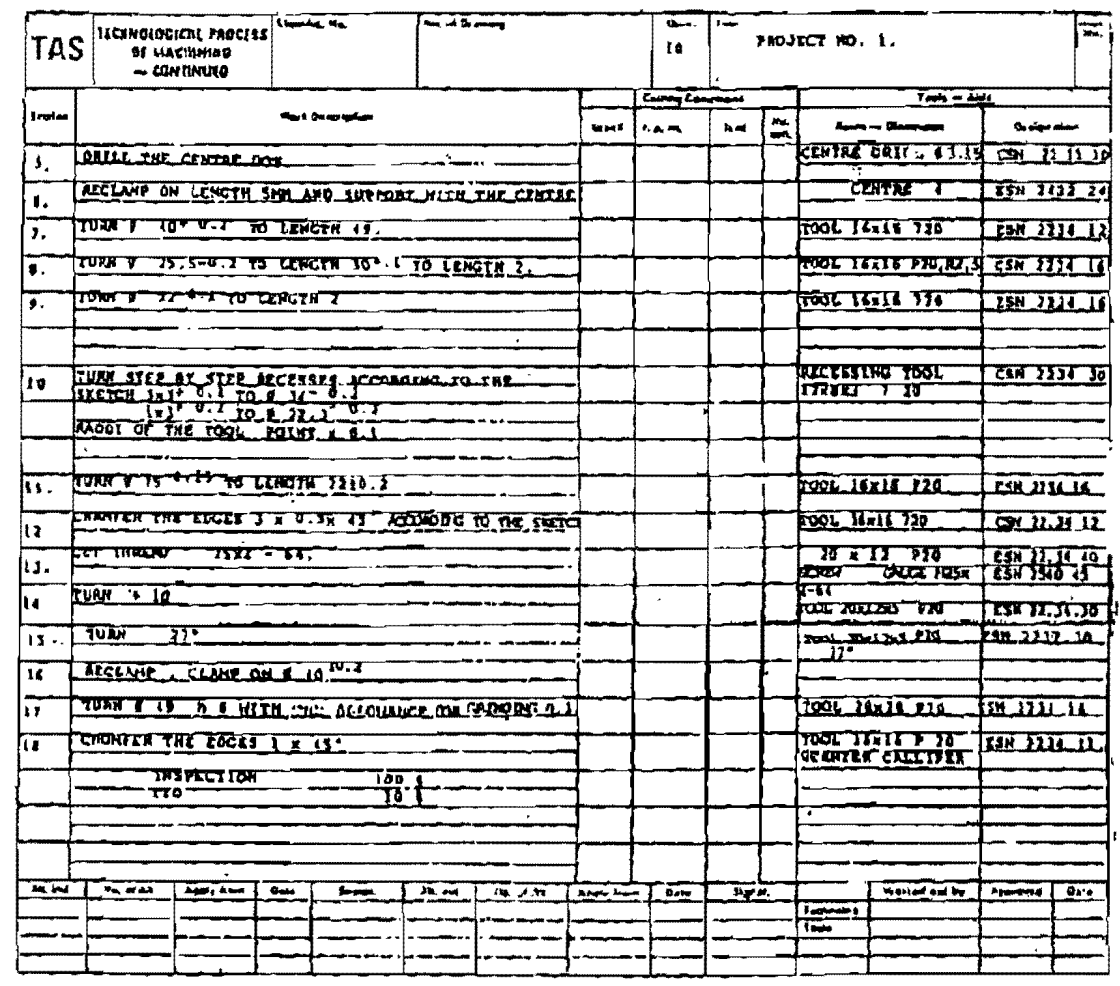

Fig. 26. 
All the information required for the cost justification has been fed to the new system and the output of the system is illustrated in appendix I. The daca used in this justification for both conventional and numerical as obtained from the factory are as shown in appendix 1

\section{Discussion and Conclusion.}

The new system (CAMTS) makes a suitable choice of the $\mathrm{m} / \mathrm{c}$ tool before constructing the process sheet (or part program) for the component. The data base of the system stores the main specificafion of each $\mathbf{m} / \mathbf{c}$ as well as the process capability of each. The IT grade corresponding to each operation has been Oslo stored in the data base memory. The system can identufy the suitable machines in the workshop or the factory satisfying the specification of the product.

The new system (CAMTS) computes the total cost of a process by finding the cost of each manufacturing operation along the process sheet. It is difficult to assign a specific value to the cost of each manufactining operation, as it will vary from one manufacturing firm to another and from one country to another. However, it is possible to work with a relative coss for each manufacturing operation as compared with a choose reference operaton.

The designed systcm (CAMTS) proved to easy used and saved a significant anjount of time and effort which could be spent to identufy the suitable opcration and $\mathrm{m} / \mathrm{c}$. It can be implcmented on a micro processor computer or compatible and it greatly reduces the range of skills required for choice the suitable $\mathrm{m} / \mathrm{c}$. Finall', it can be say that, the new system gives the process engineer a tool to ald in determining the most economic process and $\mathrm{m} / \mathrm{c}$ and it may be, a step in the way of getting a write decision in a short time and produce a complete compurer integrated manufacturing (CIM).

\section{References}

1. GROOVER, M.P. and ZIMMERS, E.W. "CAD/CAM " Computer-Aided Design and Manufacturing prentice, Inc. Englewcod clilte, New Jersey, 1984.

2. GROOVER, M.P. "Automation Production System and Computer-Aided Manufacturing "Prentıce-Hall, Inc. Englewood clifte, New Jersey, 1980.

3. HEGLAND,D.E. "Numerical Control -Your Best Investment in Productivity " Production Engineering, March, 1981, PP. 42-47.

4. Luggen, W. W. "Fundamental of Numerical Control " printed in USA by Nelson Canada, A Div of Inter. Thomson LTD. 1988.

5. El-Midany, T. T. " Variation of production cost with Batch Size for Tuming machines " 2 nd Int. Conf PEDAC.1983, Alexandria Univ., Egypt.

6. EL-Midany, T. T. and AlMakky. M. Y. " Introduction To Numerical Control of Machinc Tools " first Edition, Egypt 1994 PP.353

7. TAKEVCHI, Y. and et al. "Recorstruction of NC Lathe To BTR-DNC By means of a single Boad, 1982.

8. ARNE, N. and MAGNUS, R. "Tolerance Requirements in NC-Tuming And Grinding And Sutrable Methods of Measuring And Achieving them" proceed of fourth intermational conf., Manchester, 1988.

9. Sntherland, G.H., Roth, B., 1975, "Mechanism esign; accounting for manufacturing toler ance and costs in function generalation problem ", J. Eng. Ind. Trans. of ASME, Vol. 98,P. 282-286.

10. Kwmeth, C.L., Robert M.C. and Antany, G.A., 1987, "Manufacturing engineering ecnomics and process" Putlished by Prentice-Hall, Inc., Englewwwod Cliffs, New Jersey.

11. Oswald, P.F., and Blake, M.O., 1989, "Estimating cost associated with dimensional tolerance", Manufacturing Review, Vol. 2., No. 4, P 277-282.

12. Kunnander, A and Sohlenius, G. "Machining Reliabllity in NC-Turning." Arrals of the CIRR, vol. 28, 1979.

13. MARTAIN, S.J. "Numerical Control of Machine Tools " Hoder and Stoughton, London GB. 1979 


\section{Appendix 1.}

\begin{tabular}{|c|c|}
\hline Symbol & Definition \\
\hline $\mathrm{pl}, \mathrm{pll}$ & $\begin{array}{l}\text { are the planning costs for conventional \& } \\
\text { numerical control m/cs }\end{array}$ \\
\hline pr, prl & $\begin{array}{l}\text { are the preserting costs for conventional \& } \\
\text { numerical control } \mathrm{m} / \mathrm{cs}\end{array}$ \\
\hline$t p, t p 1$ & $\begin{array}{c}\text { are the type costs for conventional \& } \\
\text { numerical control } \mathrm{m} / \mathrm{cs}\end{array}$ \\
\hline prgl & $\begin{array}{l}\text { is the programming cost for numerical } \\
\text { control } \mathrm{m} / \mathrm{c}\end{array}$ \\
\hline$d p, d p l$ & $\begin{array}{l}\text { are the depreciation costs for conventional } \\
\& \text { numerical control } \mathrm{m} / \mathrm{cs} \text { per year }\end{array}$ \\
\hline in, inl & $\begin{array}{l}\text { are the interest rate for conventional \& } \\
\text { numerical control } \mathrm{m} / \mathrm{cs} \text { per year }\end{array}$ \\
\hline $\mathrm{mn}, \mathrm{mn} l$ & $\begin{array}{l}\text { are the maintenance costs for the } \\
\text { conventional \& numerical control } \mathrm{m} / \mathrm{cs}\end{array}$ \\
\hline or , or 1 & $\begin{array}{l}\text { are the others costs for conventional \& } \\
\text { numerical control m/cs }\end{array}$ \\
\hline wh, whl & $\begin{array}{l}\text { are the working hours of conventional \& } \\
\text { numerical control } \mathrm{m} / \mathrm{cs} \text { per year }\end{array}$ \\
\hline$|p| p \mid$, & $\begin{array}{l}\text { are the labour wages of conventional \& } \\
\text { numerical control m/cs per day }\end{array}$ \\
\hline ist, ist l & $\begin{array}{l}\text { are the initial setting time for conventional } \\
\qquad \& \text { numerical control } \mathrm{m} / \mathrm{cs}\end{array}$ \\
\hline fl, fll & $\begin{array}{l}\text { are the floor to floor time for conventional } \\
\text { \& numerical control } \mathrm{m} / \mathrm{cs}\end{array}$ \\
\hline
\end{tabular}

\begin{tabular}{|c|c|c|c|}
\hline \multicolumn{2}{|c|}{$\begin{array}{c}\text { Data of conventional } \\
\mathrm{m} / \mathrm{c}\end{array}$} & \multicolumn{2}{|c|}{$\begin{array}{c}\text { Data of NC } \\
\mathrm{m} / \mathrm{c}\end{array}$} \\
\hline Symbol & Value & Symbol & Value \\
\hline $\mathrm{pl}$ & $201.0 \mathrm{LE}$ & pll & $201.0 \mathrm{LE}$ \\
\hline pr & $0045 \mathrm{LE}$ & prl & $0.045 \mathrm{LE}$ \\
\hline$t p$ & $3.0 \mathrm{LE}$ & tpl & $42.0 \quad \mathrm{LE}$ \\
\hline $\mathrm{prg}$ & & prgl & $174.0 \mathrm{LE}$ \\
\hline$d p$ & $893.0 \mathrm{LE}$ & $d p l$ & $4285.8 \mathrm{LE}$ \\
\hline in & $803.7 \mathrm{LE}$ & in 1 & $42858 \mathrm{LE}$ \\
\hline $\mathrm{mn}$ & $243.0 \mathrm{LE}$ & $\mathrm{mnl}$ & $699.0 \mathrm{LE}$ \\
\hline or & $1890 \mathrm{LE}$ & or 1 & $378.0 \mathrm{LE}$ \\
\hline wh & $1344.0 \mathrm{hr}$ & whl & $1536.0 \mathrm{hr}$ \\
\hline lp & $12.0 \mathrm{LE}$ & Ipl & $3.0 \mathrm{LE}$ \\
\hline ist & $0.5 \mathrm{hr}$ & ist 1 & $3.0 \mathrm{hr}$ \\
\hline fl & $0.59 \mathrm{hr}$ & fll & 0.223 \\
\hline
\end{tabular}

The data used as obtained from the military factory 

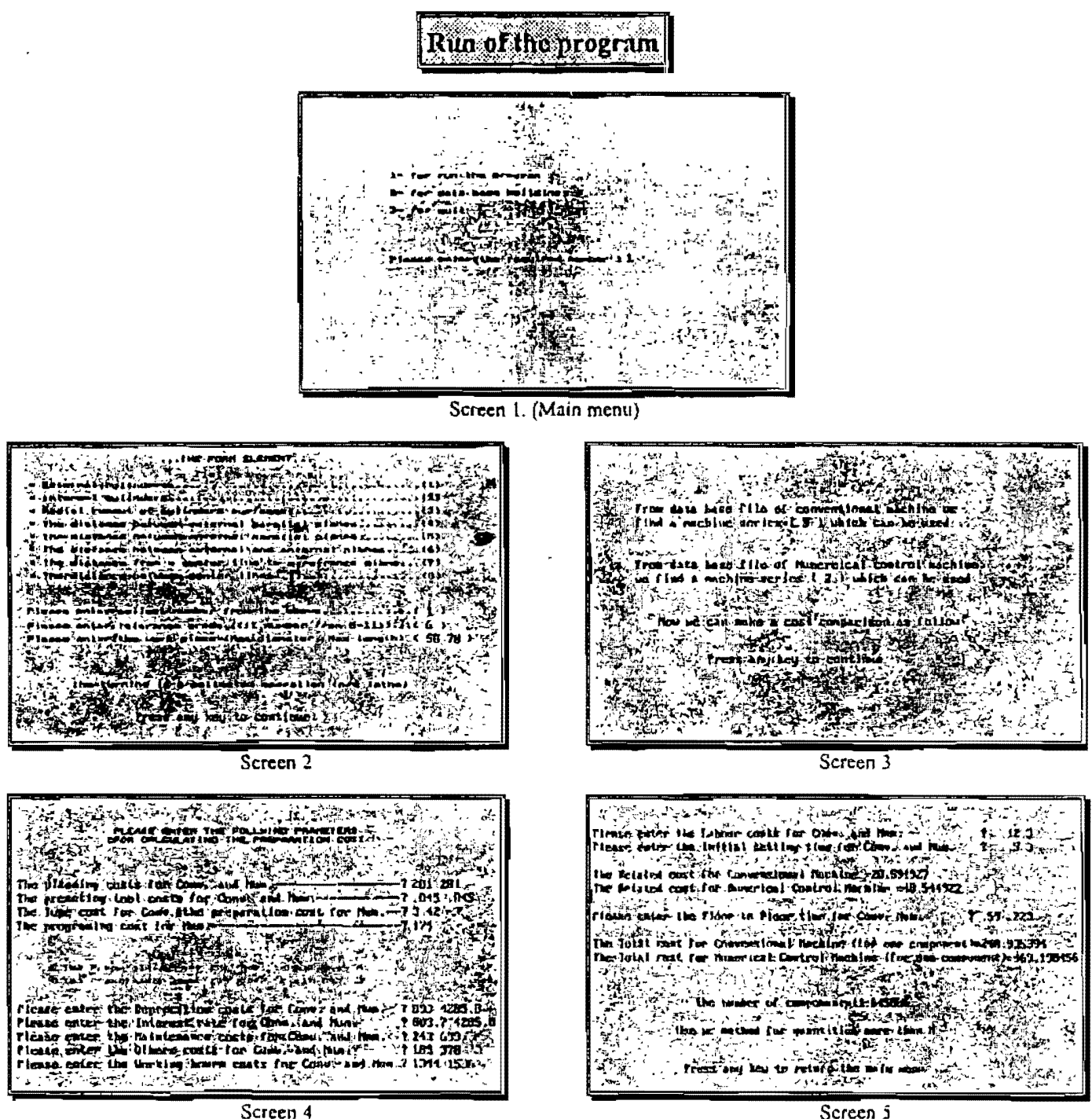

\section{Example of date base undating}

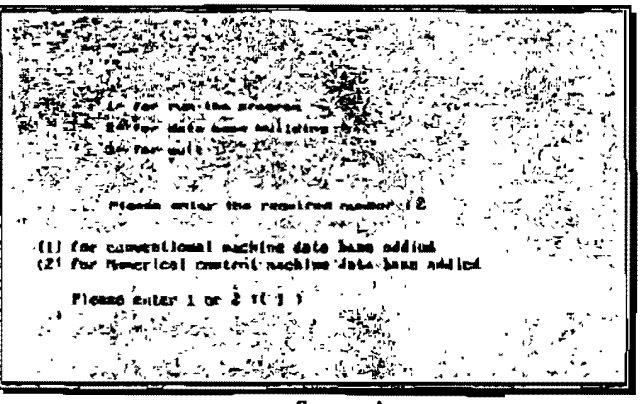

Screin !

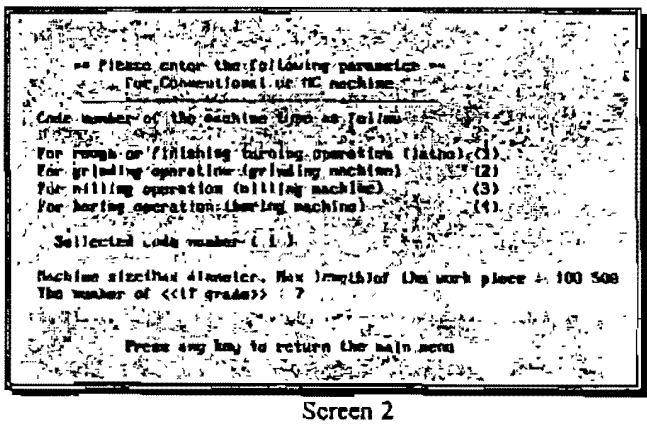

